\title{
The Impact of The Upsus National Program to The Price Risk of Red Chili in Indonesia
}

\author{
Suherman $^{a}$, Ratna Mega Sari ${ }^{b^{*}}$, Rahmah Farahdita Soeyatno $^{c}$ \\ ${ }^{\mathrm{a}, \mathrm{b}}$ Department of Agibusiness, Agricultural Faculty, University of Sultan Ageng Tirtayasa Serang-Banten \\ ${ }^{\mathrm{c}}$ Department of Agribusiness, Islamic State University of Syarif Hidayatullah, Jakarta \\ *Email : ratnatanjung@ymail.com
}

\begin{abstract}
Agricultural prices vary because production and consumption are variable (Gilbert and Morgan, 2010). Red Chili is one of the commodity that has high economic which is very volatile. Volatility refers to volatility refers to variations in economic variables over time (Policy Report, 2011). The National Upsus Program is one of the agricultural ministry programs to increase the production of some main commodities by assisting local farmers in developing irrigation systems, providing transportation access and distributing materials such as seed, fertilizers and pesticides. Red chili was one of the commodities which were selected to be developed by the National Upsus Program in 2015. This study aims to determine and compare the volatility value of the price of red chili and to analyze the impact of The National UPSUS Program in tackling of Price Risk of Red Chili. The results show that the volatility of red chili price before The National Upsus policy has ARCH (1) models. It indicates that the price of red chili is affected by the volatility of the day before. The National Upsus Program in 2015 is effective in making prices more stable. This is indicated by the value of the price of red chili which is below three so there is no heteroscedasticity. Thus the National Upsus Program is able to overcome the price risk.
\end{abstract}

\section{Keywords:Price risk, Red chili, ARCH GARCH}

\section{Introduction}

Horticulture has a big role in economy. According to the Directorate General of Hortikutura (2015), there are several factors that support the development of horticulture in Indonesia, namely (1) a number of laws, Government Regulation, and Regulation of Minister of Agriculture which become important capital in the preparation of horticulture development policy such as Law No. 12 (2) Indonesia's geographical conditions that provide a conducive environment for the growth of various horticultura, (3) Biodiversity serves as a supporter of human life (source of vitamins, mineral, nutrients, Aesthetics and health attributes) (4) Agro-ecosystem conditions that greatly support sunshine throughout the year, varying temperatures and humidity and varying sea level elevations. (5) The existence of technological support which is resulted from research institutes and agricultural development as well as the results of local wisdom from the entire potential of community and (6) market availability.

Indonesia has established several potential commodities based on economic value and high market demand. Some of the horticultural commodities that have been assigned to be excellent commodities in the period 2015-2019 are various chili, onion and orange.

According to data from Directorate General of Horticulture (2015), Chili as a potential commodity is one of the important commodities in Indonesia. The tremendous productivity trend of large chili in 2014 and 2015 has increased. Chili productivity in 2014 was 8.35 ton / ha. The productivity increased in 2015 to 8.65 ton / ha. Chili productivity also increased from 5.93 ton / ha in 2014 to 6.45 ton / ha.

Chili is a commodity that has high economic value and phenomenal. Based on the data described, red chili is a very potential commodity to be cultivated. Nevertheless farmers of red chili do not always experience the benefits. There are times when farmers often suffer enormous losses. This is related to the risks faced by farmers, especially in terms of price. The price of red chili is very volatile.

The existence of these price fluctuations is a risk faced by farmers. At times the price is very high but not long ago the price can go down drastically. Here is a picture of fluctuations in the price of red chili.

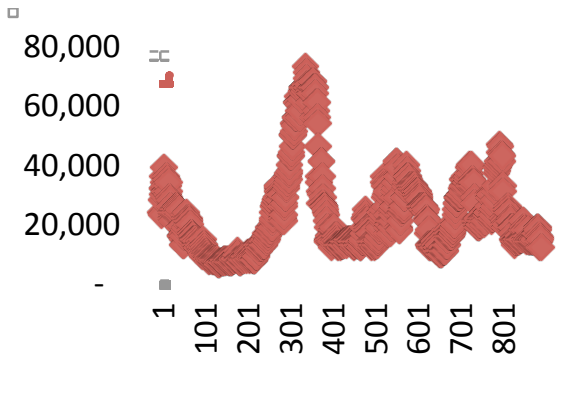

Fig 1. Plot of Red Chili Price

The National Upsus program is one of the agricultural ministry programs to increase the production of some main commodities by assisting local farmers in developing irrigation systems, providing transportation access and distributing materials such as seed, fertilizers and pesticides. Red chili was one of the commodities which 
was selected to be developed by the National Upsus Program.

This study aims to determine and compare the volatility value of price of red chili and to analyze the effect of The National UPSUS Program in tackling of Price Risk of Red Chili

\section{Methods}

Research on the risk of red chili price was conducted through data collection at Market of Induk Kramat Jati which is located at Bogor KM 17 East Jakarta highway. The location of this research was chosen because Kramat Jati Market is the biggest horticultural commodity market in Indonesia which become the benchmark of commodity price determination in Indonesia. In addition, the commodity price in Market of Induk Kramat Jati is one of information sources used by the Ministry of Agriculture in the determination of policy. The study was conducted for five months ie from November 2016 - February 2016.

The data used in this study is the daily commodity price of red chili (curly red chili and big red chili in 2011 2016. The data obtained by the record prices existing at Market office of Induk Kramat Jati. In addition, data collection is also done by interviews, observation and discussion. Interviews were conducted with several employees and traders of Market of Induk Kramat Jati as well as cultivated farmers regarding market conditions and price fluctuations of the commodities studied. The observation method is done through direct recording of market condition, while the discussion is done with the employees of Market office of Induk Kramat Jati about the market condition related to the fluctuation of price. Measurement volatility of red chili price in this research using ARCH GARCH method. There are several stages performed in the volatility analysis

\subsection{Phase Identification}

ARCH-GARCH modeling was preceded by the identification of whether the data contained heteroscedasticity or not. This can be done, among others, by observing some statistical summary of the data. Testing the existence of heteroscedasticity can be done by looking at the value of kurtosis (data kurtosis). If the data has more than three values, then the data has heteroscedasticity (Davidson and MacKinnon, 2004 in Paradise, 2006). Then, it is continued by testing the identification of the ARCH effect through the quadratic return autocorrelation function. A data has an ARCH effect if the value of autocorrelation in the quadratic data return is significant. Another way that can be done in testing this ARCH error is through ARCH-LM test. The ARCH-LM test is based on the null hypothesis that there is no ARCH error.

\subsection{Model Estimation}

There are two steps being taken in the estimation of ARCH-GARCH models namely the identification and determination stage model of the average (mean equation) and phase identification and determination of ARCHGARCH models. Identification and determination of the mean equation.

The determination of the mean equation is done by following the Box-Jenkins method. The Box-Jenkins procedure consists of several stages of data analysis, identification of the tentative ARIMA model and selection of the best ARIMA model.

\section{A. Test stationarity of data.}

Stationary data is an essential requirement in analysis of time series data to avoid spurious regression. Stationarity test of data in this study was conducted by using Augmented Dickey-Fuller (ADF-Test) test. The ADF test is performed to detect whether the data analyzed contains the unit root. The stationary data is data which is not contain the unit root.

The test hypothesis in ADF-Test is:

H0: The data has root of the unit (not stationary) and (H1) : Data has no root unit (stationary). t-statistic value which is obtained by using Eviews 6 software which is then compared with the critical value of MacKinnon. If the $t-$ statistic value in the ADF test is smaller than the critical value MacKinnon means the data is not stationary and needs to be differentiated.

\section{B. ARMA / ARIMA Model Determination}

ARIMA models tentative determination carried out on data that has been stationary based correlogram (ACF and PACF patterns) to determine the order of the AR (p) and order MA (q) of an ARIMA (p.d.q) tentative. As for the order $\mathrm{d}$ is determined based on the stationarity of the data.

After several tentative ARIMA models have been obtained, the best ARIMA model is selected. Best ARIMA model selected based on the Akaike Information Criteria (AIC) and the Schwartz Criterion (SC) with the small value. ARIMA Model selected must also meet the following criteria, namely: forecasting residual random, parsimonious models, parameters are estimated significantly different from zero, the invertibility condition and stationary have to be fulfilled which are indicated by the number of AR and MA coefficients, each of which is less than one, the iteration process should be convergence, and the model should have a small MSE.

Identification and determination of ARCH-GARCH model

At this stage, the ARCH effect test on the best ARIMA model has been obtained in the previous stage. The ARCH-GARCH model was then determined.

\section{Discussion}

\section{ARCH-GARCH Analysis of Red Chili Before The National UPSUS Program}

As described in the research method, the steps in the ARCH-GARCH analysis include: ARCH effect identification, model estimation, model evaluation, and forecasting. Explanation of the results of data analysis at each stage are as follows. The identification of $\mathrm{ARCH}$ effect is intended to test the presence of ARCH effect on the red chili price data which is analyzed in the identification period of the existence of $\mathrm{ARCH}$ effect. This is conducted by observing the value of autocorrelation coefficient of squared data analyzed. The existence of the ARCH effect is indicated by significant quadratic autocorrelation values on the first 15 periods examined from the ACF behavior and the PACF data (Firdaus, 2006).

The result of existence of ARCH effect on red chili price shows that both data indicate the existence of $\mathrm{ARCH}$ effect This can be seen from the value of autocorrelation of 
the square of the data on the price of the onion is significant in the first 15 periods indicated by the behavior of ACF and PACF. The ARCH effect test can also be performed using the kurtosis test. More than three kurtosis values indicate that the data has heteroscedasticity or there is an ARCH effect as shown in Table 1 below

Table 1. Arch Effect Test

\begin{tabular}{|l|l|l|}
\hline & $\begin{array}{l}\text { Big Red } \\
\text { Chili }\end{array}$ & $\begin{array}{l}\text { Curly Red } \\
\text { Chili }\end{array}$ \\
\hline Mean & 22175.62 & 25723.55 \\
\hline Median & 15000.00 & 20000.00 \\
\hline Maximum & 72000.00 & 82000.00 \\
\hline Minimum & 5500.000 & 900.000 \\
\hline Std. Dev & 18274.00 & 19311.48 \\
\hline Skewness & 1.290719 & 1.498776 \\
\hline Kurtosis & 3.521993 & 4.445980 \\
\hline
\end{tabular}

Model estimates follow the steps developed by BoxJenkins. The steps taken are testing of stationary of data, estimation of tentative ARIMA model, and estimation of model parameter and selection of best model. Generally, time series data has elements of trend, seasonality, and cycle. These conditions make the time series data becomes not stationary. In this study, the price of red chili data analyzed is data that has been transformed in the form of logarithm. The stationary test was performed using Augmented Dickey Fuller (ADF) test. The indicator is that if the absolute value of the ADF test statistic is less than the critical value indicates that the data is not stationary, and vice versa if the absolute value of the $\mathrm{ADF}$ test statistic is greater than the critical value, then the data has been stationary. The result of the analysis shows that the data is not stationary because the absolute value of ADF test statistic is smaller than the critical value. Therefore, it is necessary to eliminate the elements of trend, seasonality, and cycles on the price data of red chili. Elimination is done by first distinction. After one time difference, the data is stationary. The stationarity of the data will determine the degree of integration in building the ARIMA model.

Determination of tentative ARIMA model (p, d, q) was done by analyzing ACF and PACF behavior in correlogram to determine combination of AR ( $p)$ and MA (q) values. This is done after it is confirmed that the data used is stationary. In this case the data of red chili price is the data that has experienced the difference one time. Furthermore, Determination of the best ARIMA model is conducted based on some criteria, that is: random residual, simple model, the parameter is different with zero, the stationary condition must be fulfilled (AR or MA coefficient each must be less than One), the iteration process must be convergence, and the model must have the smallest Mean Square Error (MSE). Based on these criteria, then it is selected one of the best ARIMA model. Curly red chili has ARIMA model $(0,1,1)$ and big red chili has ARIMA Model $(1,1,1)$ From the best model of ARIMA, it is conducted examination on residual model. The objective is to see whether there is indeed an ARCH effect on the estimated ARIMA model. If there is ARCH effect on ARIMA model, then analysis can proceed to find ARCH-GARCH model.
Based on ARCH effect test by using ARCH LM to residual on ARIMA model, it can be estimated there is ARCH effect. This can be seen from probability value 0,0000 indicating that there is $\mathrm{ARCH}$ effect. The presence of ARCH effect indicates that the volatility of red chili price varies over time, so it can be continued to look for ARCH-GARCH model.

Next is the ARCH-GARCH model estimation using the best ARIMA model obtained in the previous stage. Determination of the right ARCH-GARCH model is done by simulating several varieties model. Estimation of model parameters using maximum likelihood or maximum quasi probability method. The model simulation combines $r=1$ and 2 , with $\mathrm{m}=0,1$, and 2 , so that six combinations of models are formed.

The selection of the best ARCH-GARCH model is done through several criteria, including: the model having the smallest SC and AIC values, has significant coefficients, the coefficient of variance and residual are not more than one and no negativity, and there is no $\mathrm{ARCH}$ effect. Based on a number of these criteria, then obtained the best ARCH-GARCH model for big red chili and curly red chili is ARCH (1) model.

Table 2. ARIMA Model and ARCH GARCH Model for Red Chili

\begin{tabular}{|l|l|l|}
\hline & Big Red Chili & Curly Red Chili \\
\hline ARIMA & ARIMA $(1,1,1)$ & ARIMA $(0,1,1)$ \\
\hline ARCH GARCH & ARCH $(1)$ & ARCH $(1)$ \\
\hline
\end{tabular}

\section{The Volatility of the Red Chili Price Before The National Upsus Program}

The result of ARCH GARCH analysis on the price of red chili which is the best model for the price volatility estimation of red chili is ARCH (1). The equation of the red chili price range model can be written as follows:

Table 3. The ARCH GARCH Equation of Red Chili Price

\begin{tabular}{|l|l|}
\hline $\begin{array}{l}\text { Red } \\
\text { Chili } \\
\text { Type }\end{array}$ & $\begin{array}{l}\text { The Best Model of ARCH } \\
\text { GARCH }\end{array}$ \\
\hline $\begin{array}{l}\text { Big red } \\
\text { chili }\end{array}$ & $\begin{array}{c}\text { ht }=\begin{array}{c}3077936+0.149387 \varepsilon_{\mathrm{t}-1}^{2} \\
(0.0000)\end{array} \\
(0.0097)\end{array}$ \\
$\begin{array}{l}\text { Curly } \\
\text { red chili }\end{array}$ & $\begin{array}{c}\text { ht }=\begin{array}{c}1709088+0.368777 \varepsilon_{\mathrm{t}-1}^{2} \\
(0.0000)\end{array} \\
(0.0001)\end{array}$ \\
\hline
\end{tabular}

This model shows that the price movement of red chili is influenced by the magnitude of one period's previous volatility. This model can be interpreted if on the price of red chili .

The probability value of ARCH parameter parameter ( 2 2t-1) and Garch (ht-1) on the model is smaller than 0.01 ( $P<0.01$, meaning that the variable is significant at 1 percent level. The number of ARCH and GARCH tribe parameters in this model has a value of not more than 1 and is not negative, so that the ARCH-GARCH model requirements are met.

Various red chili models have ARCH tribe. The value of $\mathrm{ARCH}$ coefficient on red chili variant model is 
0.149387 (big red chili) and 0.368777 (curly red chili). Based on the coefficient value ARCH can be estimated that the volatility of the price of red chili in the future will be smaller.

The Impact of The National Upsus Program To The Price Risk of Red Chili In Indonesia

The price volatility analysis of red chili in the period after the National Upsus program is applied. ARCH GARCH identification is done as a first step. The results obtained are the price data after the National Upsus Program have no heteroscedasticity. This can be seen from the value of less than three data kurtosis. The result of the analysis on the price of red chili after the implementation of the National Upsus Program shows that on the average model there is no ARCH effect, so ARCH GARCH model application can not be done. These results indicate if the volatility of the red chili price after The National Upsus Program is constant throughout the analysis period indicated by the standard error value of the average model. This indicates that the implementation of the National Upsus Program is able to control the volatility of red chili price so that the volatility becomes constant until the end of the analysis period.

\section{Conclusion}

The volatility of the price of red chili (big red chili and curly red chili) is affected by the volatility of the previous day. The introduction of the National Upsus Program led to the volatility of red chili price became constant until the final period of analysis, so the policy managed to keep the price stabilization of red chili price. Thus it can be concluded that the National Upsus policy is effective in reducing the volatility of red chili prices and minimizing the risk of red chili price in Indonesia.

\section{References}

[1] Firdaus, M, Analisis Deret Waktu Satu Ragam, IPB Press: Bogor, 2006

[2] Rencana Strategis Direktorat Jenderal Hortikultura 2015 2019. 2015. http://hortikultura.pertanian.go.id/wpcontent/uploads/2015/06/Bab-III.pdf.

[3] C.L Gilbert and C.W Morgan, Food Price Volatiliy, The Royal Society, 2010

[4] Policy Report. Price Volatility in Food and Agricultural Markets, Policy Report, 2011 